\title{
LAS REPRESENTACIONES SOBRE LOS INDÍGENAS EN LAS CRÓNICAS DE LOS MISIONEROS PROTESTANTES EN EL PERÚ A INICIOS DEL SIGLO XX*
}

\author{
REPRESENTATIONS ABOUT INDIGENOUS PEOPLE IN PROTESTANT \\ MISSIONARIES CHRONICALS IN PERÚ AT THE BEGINNINGS \\ OF $20^{T H}$ CENTURY
}

Juan Fonseca**

\begin{abstract}
Este artículo analiza las representaciones construidas respecto de los indígenas en las crónicas escritas por los misioneros protestantes que se establecieron en Perú entre 1890 y 1930. Con ese fin, analizaremos la construcción de la crónica misionera como género narrativo propio de la obra misionera protestante anglosajona en Perú durante el período señalado. Sobre esa base, mostraremos el rol esencial de las representaciones acerca del "otro" indígena en la narrativa de los misioneros protestantes. Asimismo, plantearemos pistas de cómo dichas representaciones reforzaron el imaginario colonialista concerniente al indígena que compartían los misioneros.

Palabras claves: Misiones protestantes, crónica misionera, indígena, representaciones.
\end{abstract}

This article studies the Andean world's representations in the chronicles written by protestant missionaries working in Peru between 1890 and 1920. To this end, we study the construction of the missionary chronicle as a particular narrative genre of Anglo-Saxon protestant missions in Peru during the abovementioned period. On this basis, we show how representations about the indigenous "other" played a crucial role in the narrative of protestant missionaries. Likewise, we offer clues about how those representations reinforced the colonial imagination about indigenous people, shared by both the protestant missionaries.

Key words: Protestant missionaries, missionary chronicle, indigenous people, representations.

\section{Introducción}

Desde el establecimiento de las primeras misiones protestantes en Perú se produjo una copiosa literatura escrita por los propios misioneros y que se concentraba, por un lado, en narrar sus peripecias en las -para ellos- exóticas tierras andinas y, por otro, en describir a las personas y sociedades que las habitaban y a quienes estaba dirigida su obra misional. Dicha literatura, a la que denominaré la crónica misionera, constituye un género narrativo particular con el que los misioneros construyeron sus representaciones respecto de los indígenas y el mundo andino, las que a su vez contribuyeron a reforzar los imaginarios que del "otro" indígena se tenían en Occidente y también entre la élite criolla peruana. En este artículo examinaré dichas representaciones a partir del análisis de algunos textos producidos por los misioneros protestantes anglosajones que visitaron o se asentaron en Perú entre fines del siglo XIX e inicios del siglo XX. Asimismo, analizaré cómo estas representaciones constituyeron el marco ideológico en el que los misioneros construyeron sus discursos y acciones en relación con los indígenas.

A pesar de ser parte del numeroso grupo de viajeros extranjeros que escribieron de Perú en el siglo XIX, los textos de los misioneros protestantes han sido escasamente estudiados. Los enfoques han estado, hasta ahora, centrados en los científicos, hombres de negocios, diplomáticos y exploradores, como lo muestran los trabajos de Leila Gómez (2009), Shannon Butler (2008), y Ángel Tuninetti (2001). Esto no solo en Perú. En general, en el análisis de las representaciones del otro en las sociedades poscoloniales se ha puesto poca atención a la producción cultural religiosa.

A partir del enfoque planteado por los estudios culturales, los textos elaborados por exploradores anglosajones de las sociedades periféricas (Asia, África, América Latina) se han convertido en valiosos productos culturales para comprender tanto el mundo desde donde se escribían como para

\footnotetext{
* Investigación financiada por la Dirección de Investigación de la Universidad Peruana de Ciencias Aplicadas (UPC).

** Universidad Peruana de Ciencias Aplicadas. Lima, Perú. Correo electrónico: pchejfon@upc.edu.pe
} 
conocer las sociedades "distintas" en el contexto de la expansión imperialista en el siglo XIX. El interés académico en estos textos se desarrolló inicialmente en el mundo anglosajón bajo la impronta de los estudios de Edward Said (1990) en la construcción del ideario del Medio Oriente en el mundo occidental. Dicho enfoque luego se trasladó al espacio latinoamericano con los estudios de Anthony Pagden (1993), Mary Louise Pratt (2010) y Luz Elena Ramírez (2007). Pratt, por ejemplo, analiza cómo la literatura de viajeros europeos configuró la construcción del imaginario occidental de América Latina en relación con los procesos de hegemonía colonial del continente y cómo, además, dichas percepciones configuraron la imagen de los pueblos latinoamericanos sobre sí mismos. Ramírez, por su parte, analiza la literatura británica en América Latina desde el siglo XVI al XX para mostrar la evolución de sus representaciones del mundo latinoamericano y su relación con la presencia y los intereses de la Gran Bretaña en cada contexto histórico.

Otra investigación importante es la de Rasiah Sugirtharajah (2009), quien muestra cómo los textos bíblicos fueron utilizados como una herramienta de disciplina política y cultural por parte del poder imperial británico en la India colonial. Sugirtharajah plantea una arqueología de la hermenéutica colonial para mostrar, mediante el análisis discursivo, el uso hegemonizante, pero también el disidente, de los textos bíblicos. Sobre esa base, se puede percibir la ideología contenida en la literatura religiosa protestante, lo que puede mostrarnos también las prácticas sociales concretas que surgieron de dichas representaciones.

Asimismo, considero fundamental el aporte de Anna Johnston (2003), quien en su estudio de los escritos producidos por los misioneros de la London Missionary Society (LMS) en el siglo XIX plantea que dicho corpus literario puede ser considerado como un género narrativo específico, al que denomina literatura misionera (Missionary writing). En dicho género se combinan los rasgos narrativos de la etnografía misionera y la literatura de viajes para construir un discurso que buscaba autojustificar la obra misionera dentro de los procesos de colonización, pero que no fue necesariamente homogéneo, pues en el encuentro con las sociedades coloniales, el discurso colonial de los misioneros también se transformó y, sobre esa base, alteró ciertas teorías y políticas de la metrópoli imperial.
En el espacio andino, algunas contribuciones recientes son las de Antonio Migliori (2013) y Felipe Maturana (2016). Migliori analiza cómo las descripciones de paisajes del Andes peruano elaboradas por viajeros extranjeros en el siglo XIX definieron las representaciones de la geografía y la población de la región andina. Maturana, por su parte, examina el proceso de construcción de las representaciones visuales de los uru-chipaya desde la época colonial hasta mediados del siglo XX por medio de la fotografía ${ }^{1}$.

Para enriquecer el análisis aplicaré la metodología del análisis crítico del discurso (ACD), disciplina sociolingüística que plantea básicamente que el lenguaje en uso (el discurso) es un mecanismo en donde se refuerzan o sustentan las relaciones de dominación dentro de las sociedades. Desde la perspectiva de Norman Fairclough, el discurso es una concepción tridimensional pues involucra tres niveles: el texto, la práctica discursiva y la práctica social. El primer nivel corresponde a la "tradición de análisis textual y análisis lingüístico", el segundo a la "tradición macrosociológica de considerar a la práctica social en relación con las estructuras sociales" y el tercero a la "tradición interpretivista o microsociológica que considera a la práctica social como aquello que es producido y decodificado activamente por las personas sobre la base de una noción de compartir un sentido común" (Fairclough, 1992: 9). En ese sentido, el discurso no solo se configura como una representación de la realidad, sino también como práctica ideológica que "constituye, naturaliza, sostiene y cambia los significados del mundo desde las diversas posiciones en relaciones de poder" (Fairclough, 1992: 4). Así, al analizar el discurso de los misioneros en la población indígena, no solo queremos determinar cómo esta era representada, sino cómo dicho discurso articuló el imaginario de aquella desde la perspectiva del misionero con la producción de prácticas sociales concatenadas con dicho imaginario.

\section{Los misioneros protestantes como agentes culturales}

A lo largo del siglo XIX, la ola misionera protestante se extendió por el mundo en paralelo con la expansión de las potencias imperiales protestantes: Gran Bretaña, Alemania y Estados Unidos. En Perú, hacia 1915, el 90\% de la fuerza misionera 
protestante era estadounidense o británica. Los primeros misioneros protestantes que visitaron Perú fueron los denominados colportores (vendedores de biblias) de la Sociedad Bíblica Americana (SBA) y la Sociedad Bíblica Británica y Extranjera (SBBE). Su labor se circunscribía solo a distribuir la Biblia. A diferencia de ellos, los misioneros adscritos a una agencia misionera sí buscaban establecerse de manera permanente en el país. Algunos, como el metodista William Taylor, exploraron Perú en la década de 1870, pero la Guerra del Pacífico interrumpió dichos intentos.

Luego del fin de la guerra, los colportores reaparecieron. Uno de ellos, el metodista ítalouruguayo Francisco Penzotti, estableció en 1889 la primera congregación protestante conformada por peruanos $^{2}$. Desde entonces, misioneros de diversas agencias se establecieron en el país, principalmente metodistas, evangélicos independientes y adventistas. En 1913, sin contar a los adventistas, 43 misioneros trabajaban en Perú (Fonseca, 2002: 133). Sobre la base de la tipología propuesta por Míguez Bonino (1995), en este período predominaron los misioneros de la vertiente liberal, principalmente representada en el metodismo, mientras que la línea evangélica estuvo predominantemente representada por los misioneros de la Evangelical Union of South America (EUSA). Los adventistas estaban más cerca a lo evangélico, aunque con las particularidades de su doctrina milenarista.

En todos los países donde se establecieron los misioneros protestantes tuvieron un rol importante como agentes culturales durante el período de expansión del imperialismo occidental, tanto en las metrópolis como en las periferias. En las metrópolis, los misioneros eran considerados agentes necesarios en la estrategia de expansión de las potencias imperiales. En ese sentido, el rol del misionero no solo se circunscribía a la difusión de un mensaje religioso, sino también, y principalmente, a su función como "civilizador". Según Jean Pierre Bastian, el misionero protestante estadounidense llegaba:

(...) convencido de que participaba en una cruzada cuyo objetivo se relacionaba con los cimientos de la civilización norteamericana, capitalista y cristiana, de la que él debía transmitir lo mejor. Percibía que la orientación de sus actos continuaba la lucha que acababa de librarse por la cristianización del oeste norteamericano, y que la prolongaba en un continente que también debía pasar de la barbarie a la civilización. Esta reforma, de la cual él era agente transmisor, se fundaba en la Biblia y en el Evangelio, traicionados y negados a los indios, según él, por la Iglesia Católica (Bastian, 1990: 112).

En ese sentido, los misioneros contribuyeron a reforzar el sentido ético de la expansión imperialista ${ }^{3}$. Como lo señala Jamie Scott
“(...) bajo el doble eje de la "biblia y la bandera', gobiernos, comerciantes, explo- radores y otros aventureros explotaron el aura de responsabilidad ética provista por la religión para cada esfuerzo de llevar la civilización británica a un mundo igno- rante" (en Johnston, 2003: 13) [traducido por el autor].

Uno de los recursos discursivos fundamentales utilizados por los misioneros para contribuir en la "eticización" de la expansión imperial de Occidente fue la literatura.

\section{La crónica misionera como género narrativo}

Las crónicas misioneras se ubican dentro de la categoría más amplia de la literatura de viajes. Este corpus literario ha sido analizado en dos niveles. Primero, a partir de enfoques intradisciplinarios, tanto como fuente primaria (desde la historia) como género literario (desde la literatura). Segundo, desde un enfoque interdisciplinario, como un producto discursivo que se apropia de las sociedades y espacios no occidentales a partir de las representaciones que construyen sobre ellas los agentes del colonialismo, es decir, los viajeros occidentales. Dentro de este último enfoque, sustentado en los estudios poscoloniales, la literatura de viajes se considera como parte del corpus literario imperialista que construyó al mundo no occidental a la imagen de Occidente para facilitar los procesos de expansión imperial (Ramírez, 2007).

En Perú, entre 1890 y 1930 se publicaron 31 crónicas escritas por misioneros que habían trabajado o trabajaban en el país. Adicionalmente, muchos misioneros más publicaron crónicas más breves bajo la forma de artículos en alguna de las revistas oficiales de las agencias misioneras a las que pertenecían: Inca Land, de la Iglesia Metodista Episcopal 
(Estados Unidos) y The Neglected Continent y South America, de la EUSA (Gran Bretaña). Uno de los rasgos de las crónicas misioneras fue que estuvo destinada al público de sus países originarios: Gran Bretaña y Estados Unidos, principalmente. Por ello, siempre fueron publicadas en inglés. El proceso de producción del texto estaba condicionado a los procedimientos de las instituciones eclesiales a las que estaban adscritas los misioneros. Algunas veces, la redacción del texto era promovida por los altos funcionarios de las misiones; otras veces, partía del propio interés de los misioneros por dar a conocer sus experiencias e impresiones del país. Los lugares de distribución solían ser la propia agencia misionera o las librerías religiosas. En algunos casos, los libros eran publicados como suplementos de una revista misionera. Si era así, podían llegar a un público específico como parte de las suscripciones de los socios donantes de la misión. Muchas veces, los propios autores se encargaban de distribuir sus libros durante las giras que hacían para animar a las parroquias o congregaciones a aportar para la obra misionera ${ }^{4}$.

Entender todo este proceso es importante porque los textos misioneros no expresaban puntos de vista individuales. Eran parte de una institucionalidad y un espacio social determinado que compartía formas de ver el mundo y un estilo de interrelaciones muy concreto. Los textos eran parte de un circuito de producción e intercambio de ideas y representaciones.

\section{Las características del género}

Las crónicas misioneras respecto de Perú compartían ciertas características comunes. Por ejemplo, los títulos hacían referencia al sentido épico de las misiones o al imaginario andino: $U p$ and Down the Andes on a Burro (Maxwell, 1921), For Christ and Cuzco (Newell, 1904), The Children of the Sun (Guinness, 1906) o In the Land of the Incas (Stahl, 1920). Las constantes de este género también se reflejan tanto en la estructura como en los recursos lingüísticos utilizados en los libros. Como muestra, tomaremos al texto de John Jarrett, Fifteen Years in Peru. The Story of a Struggle on Behalf of Religious Liberty (1908) ${ }^{5}$. Su estructura de capítulos es como sigue ${ }^{6}$ :

- Testimonio personal de la vocación a la misión: "Porque ellos salieron por amor del nombre de Él”- 3ra. Jn. 7.
- Relato de la persecución en el Cusco: "Perseguido pero no detenido".

- Salida exitosa del Cusco: "Problemas en todos lados, pero no preocupados".

- Perfil sociocultural del Cusco y situación de la misión: "Dios... dio el crecimiento".

- Trabajo entre los indígenas: "El llanto de los indios. Vengan y ayúdennos".

- Situación en el resto del país: "El llamado de las ciudades".

- Reporte del trabajo misionero y solicitud de donaciones: "Más allá de los campos".

En el texto de Jarrett, así como en los de Guinness (1909) y Browning et al. (1930), se visibilizan los elementos típicos de la crónica misionera, que son los siguientes:

- El protagonismo personal. Los textos siempre están en primera persona, ya sea en singular o plural: Nosotros, yo, nuestro, nos, a mí, etc. Los autores se erigen como protagonistas de su propia narración. Usualmente, se inician con el llamado vocacional en el país natal del misionero y culminan con su retorno a él. Suelen hacer referencia a la intervención divina en su recorrido, pues asumen que es parte de un plan de Dios para ellos y para la gente del país.

Y enfrentar al Perú implicó fe. Salimos sin ninguna organización detrás de nosotros, $\mathrm{o}$ que nos garantizara apoyo; y Perú apenas podría ser considerado o presentado como una puerta abierta. (...) Sabíamos de las necesidades del Perú, y entonces salimos para encontrarnos con ellas, con los buenos deseos y la simpatía de los directores de la RBMU, y con la plena dependencia de Aquél Quien no da nuestro pan cotidiano, y Quien quiere que todos los hombres vengan al conocimiento de su Verdad (Jarrett, 1908: 4) [traducido por el autor].

- La narración heroica. Los relatos construyen un escenario hostil en el que el misionero emerge como un héroe. Los obstáculos que debe vencer son diversos. Uno de los más comunes es la naturaleza agreste.

Qué difícil me pareció ese extenso viaje en mi frágil condición, pero sin embargo logré atravesar las quinientas millas seguramente. (...) Primero congelados por el 
frío, luego derretidos por el calor, a veces mojados por la lluvia o agobiados por la sed, continuamos hasta que el viento, el sol, la lluvia y la nieve en rápida y sucesiva combinación transformaron nuestras ropas y rostros en un color polvoriento (Jarrett, 1908: 7) [traducido por el autor].

También es frecuente la mención a la vigorosa oposición de las autoridades locales, del clero católico y la población en general.

Él [un compañero misionero] murió de tifoidea en el hospital. Durante su enfermedad, sacerdotes y monjas -porque, obviamente, el hospital era católico- trataron de "convertirlo", pero sus últimas palabras, pronunciadas al oído, fueron: "La sangre de Jesucristo, Su Hijo, nos limpia de todo pecado (Jarrett, 1908: 7) [traducido por el autor].

- La descripción geográfica. No solo se describen las formas del relieve o la diversidad del clima, sino que se construye una narrativa que exotiza el espacio peruano. En ellas, la geografía va más allá de la mirada del científico o del explorador. Busca también construir un escenario espacial para lo central de la narrativa: la épica del misionero.

Ningún lugar en el mundo combina tal diversidad de bellezas e intereses como el Perú. En la Montaña podemos seguir el rastro del tigre hasta el vado donde el venado acude a beber; o apenas escapar de la boa constrictora o la letal serpiente de agua. En la Sierra podemos cabalgar por días enteros sobre llanuras más elevadas que la cumbre del Mont Blanc; visitar valles azucareros que están al mismo nivel que el cráter del Fujiyama; o navegar a través de las nubes sobre un lago cuarenta veces más alto que el pináculo de San Pablo [la catedral londinense]. En la Costa podemos viajar a través de un desierto tan solitario e impresionante como el Sahara; o recoger algodón, café y piñas en plantaciones de belleza tropical (Guinness, 1909: 8) [traducido por el autor].

- La etnografía. Los misioneros dedicaron una gran parte de su narrativa para describir las características de los pueblos y sociedades en los que realizaban su obra misional. Sus textos suelen enfocarse en la situación de la población indígena para resaltar el abandono en el que viven del que responsabilizan principalmente a la Iglesia católica. No obstante, teniendo en cuenta que es el grupo en donde enfocaron principalmente su actividad misionera, asumen también que su redención es posible por medio de la educación y el cambio religioso.

Los indios peruanos cargan hoy las marcas de su larga opresión y explotación. Su ambiente desolado, su adicción al alcohol, y sus hábitos de mascar hoja de coca con un poco de potasa -así produciendo cocaína en su boca-han degradado y atontado a muchos de ellos. Sin embargo, el indio es la esperanza del Perú. Recibiendo oportunidades para la educación y el mejoramiento, inspirado con una nueva esperanza y ambición, su industria y tenacidad lo levantarán en un buen lugar (Browning et al., 1930: 60) [traducido por el autor].

- El diagnóstico religioso. La situación religiosa fue uno de los énfasis en la narrativa misionera. En sus crónicas, los misioneros se alineaban con el discurso de la elite liberal criolla en el sentido de asociar la "decadencia" del indígena con la religiosidad católica.

La única esperanza del Cusco es que el romanismo, con su impía camada de sacerdotes y monjes, sea eliminado. Ninguna reforma es posible a un sistema como ese; ninguna luz puede venir desde ese foso de oscuridad. (...) Los indios requieren nuestra ayuda-incluso los librepensadores peruanos están deseosos de admitir que los evangélicos poseen algo que puede levantar a los indígenas (Jarrett, 1908: 15, 19) [traducido por el autor].

- La apelación al compromiso. Todas las crónicas cierran con un llamado, no siempre explícito, a sus lectores - protestantes británicos o norteamericanosa contribuir con la causa misionera.

"Oraréis de esta manera". Que la lectura de esta corta narración te mueva a orar en nombre del Perú, y mientras oras piensa si está en su poder ayudar a responder esa 
oración (...) Se necesita urgentemente fondos para mantener y extender la obra y serán gustosamente recibidos (Jarrett, 1908: 24) [traducido por el autor].

\section{Los indígenas en las crónicas misioneras: lo textual y lo ideológico}

Uno de los aspectos más resaltantes en las crónicas misioneras es su especial énfasis en la población indígena. En ese sentido, podrían establecerse paralelos con las crónicas de Indias, que entre los siglos XVI y XVII construyeron una narrativa respecto de la América indígena de entonces. El análisis discursivo de sus crónicas permite desmenuzar el proceso cómo los misioneros construían sus representaciones hacia los indígenas. Para mostrarlo aplicaré la metodología del ACD (Fairclough 1992) a algunos fragmentos de la crónica de John Jarrett (1908).

\section{En el nivel textual: lexical y gramatical}

Los misioneros utilizan un vocabulario específico para nominalizar a los grupos con los que interactuaban y a quienes representaban en sus textos. Estos grupos eran básicamente cuatro:

- Los miembros del clero católico. Son representados siempre de manera negativa, como fanáticos, hipócritas, corruptos y enemigos de los indígenas.

Cuzco's only hope is to be rid of Romanism with its unholy brood of priests and monks. (...) I have met priests there who were vile enough to boast of the number of girls they had ruined, whose lives were one long debauch, and who boasted of grand prosperity in the line of sin, when about to go on a mission to an Indian village. I have no met one GOD-fearing man amongst them who could remain in the system. (Jarret, 1908: 15)

- Los agentes del Estado. Son colocados en un contexto en el que se resalta su inoperancia y su sumisión al clero católico. En su relación con los indígenas se los coloca junto al sacerdote y al hacendado como causantes de perjuicios hacia los indígenas.

For centuries he has been oppressed by priests and local authorities alike, and is in reality the property of the owner of the land upon which he lives, since in order to occupy a miserable hut (...) we have seen them (a los indígenas) whipped by a cruel governor until the blood flowed from face and body (Jarrett, 1908: 17-18).

- Los propios misioneros. Enfatizan su rol positivo como agentes éticos y casi salvadores predestinados de la población indígena.

The Indian requires our help-even the freethinkers of Peru are willing to admit that the evangelicos possess something that may lift the Indian up (Jarrett, 1908: 19).

- Los indígenas. Son descritos de manera negativa, pero enfatizando su papel de víctimas. Abundan las descripciones de su fanatismo, falta de higiene, pobreza, ignorancia, etc. Al nominarlos constantemente como "Hijos del Sol", los cronistas misioneros realzan el contraste entre un pasado glorioso y un presente decadente.

Piteous indeed is the cry of the Quechua Indian of Peru, the only remaining representative of her famous Inca race. There he stands, the victim not only of greed but of vice-illiterate, dirty, idle and brutish- the result of centuries of ill-treatment, slavery and abuse (Jarrett, 1908: 17).

A partir del análisis de la transitividad en las cláusulas de los artículos, podemos observar que los misioneros suelen ubicar los indígenas en una posición subordinada anulando su agencia.

- Papeles temáticos. Los indígenas casi nunca aparecen como agentes. Suelen ser representados como víctimas o como beneficiarios.

\section{Agente Beneficiario}

There the evangelization of the Indian is to begin. There (la base misionera) he (el indio) will be well treated, educated and trained, and he and his children taught to believe in a Saviour from sin. (Jarrett, 1908: 18).

$$
\text { Agente }
$$

(...) we have seen them (a los indígenas) whipped by a cruel governor until the blood flowed from face and body (Jarrett, 1908: 18). 
- Procesos. Se enfatiza el papel del agente (misioneros o sacerdotes) en las acciones de los indígenas. La agencia de los receptores es prácticamente nula.

The idea is to influence the Indians by inviting them to settle down with their families upon a few acres of the land, for which they will give a certain amount of labour in return. The missionaries will live in close contact with these settlers, and with the help of native Christians, speaking both Spanish and Quechua, will teach them the truths of Christianity, at the same time caring for their needs, educating their children, and doing their utmost to make them realize the love of God (Jarrett, 1908: 23).

\section{En el nivel ideológico}

Las representaciones de los misioneros en la población indígena se formaron sobre la base del imaginario cultural anglosajón y de los postulados del naciente indigenismo. Además, compartían con la intelectualidad positivista la tendencia a explicar la compleja situación de los indígenas con argumentos racistas. En uno de los reportes del Comité de Cooperación en Latinoamérica (CCLA por sus siglas en inglés) se afirma que "el indio quecha está muy encima del negro australiano en la escala de seres inteligentes, tal vez algo por arriba de los cafres y hotentotes y del indio norteamericano, pero debajo del maorí de Nueva Zelanda" (CCLA, 1925: 170) [traducido por el autor]. Además, los misioneros solían desdeñar los hábitos ancestrales andinos como el consumo de la coca, las creencias religiosas y las festividades. El misionero metodista Marvin Rader los describía de esta manera:

Todos los indios me parecen flacos y hambrientos, sin embargo, aún es inusual un verdadero estado de inanición. Pero vivir en la suciedad y la podredumbre, la ignorancia y la pobreza, la superstición y el temor, en una vida puramente animal, no es lo que Dios desea para los seres humanos. (...) Han sido explotados por la codicia y descuidados por la iglesia. Continuarán viviendo en niveles tan bajos hasta que reciban educación y justicia (Rader, 1926: 20) [traducido por el autor].
La percepción de este misionero es similar a la de la mayoría de los intelectuales criollos de la época. No obstante, en el análisis de la problemática social, la influencia de las ideas indigenistas es más ostensible pues señalan como causa de su atraso la falta de educación, el alcoholismo y la explotación de las autoridades, en particular las religiosas (Fonseca, 2005).

Sin embargo, no todo era negativo en las representaciones acerca de los indígenas de los cronistas misioneros. También ofrecieron descripciones positivas pero paternalistas, infantilizándolos: " $\mathrm{Si}$ en muchos casos la opresión ha tendido a dañar la naturaleza infantil y el espíritu dulce de los indios, también ha evidenciado sus cualidades más nobles: paciencia, gratitud y fidelidad" (Guinness, 1909: 188) [traducido por el autor]. Solo en el caso de algunos personajes específicos, en los que se resaltaba su condición de "redimidos" por la educación, los misioneros resaltaron sus cualidades positivas. Ese fue el caso de Francisco Chuquihuanca Ayulo, abogado y político puneño, quien se unió a la Asociación Pro-Indígena en 1910 y, desde entonces, respaldó decididamente al movimiento indigenista. Además, consecuente con su liberalismo político y su anticlericalismo militante, apoyó a los misioneros adventistas atacados por turbas católicas en Platería (Puno) en 1913, incidente que derivó luego en la aprobación, en 1915, de la reforma constitucional que garantizó la tolerancia de cultos en Perú (Arroyo, 2005: 49-50). Chuquihuanca, además, reivindicaba su condición de descendiente de la realeza incaica. En las crónicas misioneras se le menciona como ejemplo de lo que puede hacer la educación y la liberación del catolicismo en el indígena, evocando a su vez la "nobleza" de su ascendencia: "Señor Francisco M. Ch. Ayulo, un indio puro, y descendiente directo de Huayna Cápac, el duodécimo emperador de la dinastía inca, está también profundamente interesado en este naciente movimiento [protestantismo misionero] para ayudar a su raza" (Guinness, 1906: 216) [traducido por el autor].

El caso de Chuquihuanca refleja a su vez los rasgos de las representaciones del pasado andino en las crónicas misioneras. Los cronistas misioneros utilizaron principalmente la visión del historiador inglés Clement Markham (Guinness, 1909: 21, 66, 184, 189). En su percepción, un pasado incaico brillante se confrontaba con la sombría existencia de los indígenas durante el virreinato. Los obrajes, la 
mita minera, el sistema de tributación y la represión de la revuelta de Túpac Amaru, fueron aspectos especialmente resaltados por algunos misioneros empeñados en mostrar la "bárbara" condición en la que cayeron los indígenas bajo el dominio español (Fonseca, 2005).

Por otra parte, la percepción del estado religioso de los indígenas fue el asunto que más desarrollaron los misioneros (Piedra, 2005). Desde su visión, la religión practicada por los indígenas era un "cristianismo paganizado" (Guinness, 1909: 173) [traducido por el autor]. No comprendían cómo, luego de varios siglos de evangelización, las ceremonias y festividades católicas se mezclaban con devociones andinas que culminaban con borracheras colectivas. Las propias devociones católicas les parecían idolátricas y las comparaban con su propia religiosidad, austera y práctica. Es la misma postura de Mariátegui en los Siete Ensayos cuando señala que el catolicismo colonial fue eminentemente ritual, mientras que el protestantismo era una religión práctica y fundamentalmente ética (Mariátegui, 1955[1928]: 169-185). Así, los protestantes sostenían que la mejor alternativa religiosa para "civilizar" a los indígenas y, de paso, "modernizar" al país, era la difusión de la oferta religiosa protestante. Un misionero lo expresó así:

[el catolicismo] no es la religión que conviene para los indígenas, minando la salud y virilidad de la raza de este mundo, y condenándoles en el otro a pesar de todo "misticismo". (...) Sabemos que razas muy inferiores a nuestros indios han sido convertidos, por la predicación del evangelio puro, a una vida de utilidad, inteligencia y de santidad práctica. (...) [Con la separación de la Iglesia del Estado], millares de peruanos se sentirían más libres para "escoger su religión" y no dudamos que el protestantismo, o el evangelio puro y no mercenario- tendría su día (Smith, 1918: 68-69) [traducido por el autor].

\section{En el nivel de la práctica social}

Sobre la base de los niveles anteriores, los misioneros protestantes desarrollaron una intensa labor misional dirigida hacia los indígenas, la que fue extensamente difundida en sus crónicas. Un ejemplo de ella fue la Hacienda Urco en Calca, adquirida en 1908 e inscrita como The Inca Schools Society -Sociedad Pro-Indígena de Agricultura e Instrucción-. En dicha hacienda los misioneros introdujeron innovaciones técnicas para la agricultura de la región a la vez que educaban a los niños indígenas acogidos por ellos. Los misioneros no solo buscaban formar "técnica" y "científicamente" a los indígenas, sino también inculcar en ellos "hábitos civilizados" como la abstinencia alcohólica, la puntualidad y la disciplina laboral, así como alejarlos de sus celebraciones religiosas tradicionales (Fonseca, 2005).

La EUSA también intentó establecer una obra entre los indígenas de la selva. En 1913, a raíz de las denuncias de Sir Roger Casement respecto de la explotación de los indígenas por los caucheros de la selva peruana, la EUSA envió una expedición dirigida por tres misioneros a la zona del Putumayo para comprobar in situ las atrocidades denunciadas y establecer una misión. A pesar del entusiasmo que se manifestó en las numerosas donaciones recibidas para sufragar sus gastos, la expedición no tuvo éxito. Posteriormente, en la década de 1920, misioneros de otras agencias (Iglesia del Nazareno, Alianza Cristiana y Misionera) retomaron sus incursiones hacia las etnias indígenas amazónicas. Finalmente, los adventistas desarrollaron una impresionante obra educativa entre los indígenas de Puno, que fue ampliamente elogiada por los indigenistas (Fonseca, 2005).

\section{La ideología en la representación del indígena en las crónicas misioneras}

De esa manera, mediante el desarrollo de un discurso que combinaba compasión y desdén, los misioneros protestantes crearon una "zona de contacto" (Pratt, 1997), dentro de ella no solamente justificaban la naturaleza religiosa de su incursión al mundo del "otro" indígena pagano, sino también se articularon como parte del sustento ideológico del proyecto modernizante de la República Aristocrática y el Oncenio. Dicha zona de contacto configuró una interacción asimétrica entre la presencia hegemonizante del misionero y la subordinada del indígena-pagano-salvaje.

Este mecanismo religioso fue, para muchos de los intelectuales de la época, una de las formas más eficaces de "civilizar" al indígena. Así lo afirmaba José Antonio Encinas: 
El problema de la regeneración de la raza no puede resolverse sino dentro del criterio religioso mientras la conciencia del indio no adquiera la fuerza necesaria para guiarse sin este control. Solo sí hay que comenzar por apartarlo de toda supertición (sic). Por independizarlo de todo aquello que las prácticas religiosas absurdas han dejado como sedimento en su conciencia. Felizmente esta labor la realizan admirablemente los diferentes grupos de protestantes que viven en el Perú. (...) Yo hago un llamado a la juventud de mi patria para apoyar esta obra de los protestantes. Ellos nos han de devolver a los indios convertidos en ciudadanos útiles para el país. No averigüemos si el indio ha de resultar protestante ó nó (sic), averigüemos si ha dejado sus vicios, su incuria, si ya sabe el nombre del suelo que pisa, las leyes que lo cobijan, los derechos que tiene (Encinas, 1915: 5-6).

Es decir, para la elite modernizadora de la época, el discurso protestante parecía ser mucho más efectivo que el católico, no solo para civilizar, sino para formar una comunidad política de ciudadanos. Para otros, como Luis Valcárcel, la prédica protestante incluso va más allá, no solo civiliza, sino incluso "humaniza":

El adventista está ayudando al alumbramiento del nuevo indio. Su asepsia se deja ver en la extirpación de los vicios seculares: alcoholismo, cocainismo, servilismo. El hombre que en la altipampa del Kollau representa hoy la tradición milenaria del Tiwanaku, posee hábitos higiénicos, viste de americana, reside en limpias moradas, no bebe aguardiente ni pijjcha coca: es abstemio. Ha aprendido a mirar de frente, a hablar con aplomo y a extender la mano en gesto amistoso a cuantos favorece con su simpatía. Es un hombre (Valcárcel, 1972 [1927]: 132).

Estas apreciaciones muestran que el apoyo de la intelectualidad indigenista a la obra protestante se basó en su mutua comprensión de que lo indígena se encontraba en una escala cultural inferior y que su "redención" consistía básicamente en una conversión cultural, un proceso de autoexpropiación de sus tradiciones milenarias para convertirse en hombres "modernos" y "civilizados". La educación y la ética provista por los agentes religiosos protestantes era conveniente para promover entre los indígenas una progresiva separación de las costumbres que lo "degeneraban" y prepararlo para la vida moderna. En el aspecto político, se buscaba que el indígena sea obediente a las leyes y se identifique con la patria. En el aspecto económico, el objetivo era formar en él costumbres que lo acostumbraran al trabajo, el ahorro y la disciplina; es decir, hábitos que lo capaciten para incorporarse a un sistema de trabajo libre, y alejarse del cuestionado sistema de servidumbre propio del latifundismo tradicional (Fonseca, 2005).

Sobre esa base, el discurso del "paganismo salvaje" contribuyó decisivamente en la autocomprensión de la naciente comunidad protestante nativa de ser una comunidad de "nuevos hombres", ahora civilizados y auténticamente cristianos. Así, la representación que los misioneros anglosajones foráneos construyeron en los nativos, terminó creando hegemonía en el sentido gramsciano.

\section{Reflexiones desde un enfoque poscolonial}

Las crónicas misioneras son una fuente historiográfica inestimable, no solo por la información que provee sino también para conocer la interacción entre los productores y sus receptores. De acuerdo con los criterios de Ranajit Guha (1999), la crónica misionera estaría dentro del discurso secundario de la literatura histórica. Así, el texto no solo es una fuente histórica para conocer aspectos de la vida de la población indígena sino también una ventana para conocer los mecanismos de subalternización que dicha población sufrió en un momento determinado de su historia. En otras palabras, no podemos hacer una historia de la población indígena peruana solo a partir de los relatos de los misioneros extranjeros $\mathrm{y}$, en general, los viajeros extranjeros y los intelectuales criollos respecto de ella. En todo caso, sería una historia legitimadora del modelo civilizatorio occidental, si es que no tenemos la contraparte: la voz del indígena en el texto.

Pero aun si tuviéramos la "voz del indígena" por medio de fuentes históricas en las que ellos hablen, tampoco podríamos afirmar que estamos haciendo una historia auténtica de esa población subalternizada. No se puede, primero por la dificultad objetiva de obtener dicha "voz del indígena". 
Al menos dentro de la tradición letrada protestante, no existen escritos de indígenas al menos hasta mediados del siglo XX. Cuando aparecieron algunos textos formulados por protestantes peruanos nativos, la visión que plantean de ellos mismos es tan, o a veces más "civilizatoria" que la de los propios misioneros. Gayatri Spivak (1988) tenía razón al afirmar que el subalterno no habla, al menos si seguimos aplicando una metodología tradicional. En todo caso, como hemos visto en las citas pertinentes a los indígenas, solo podemos reconstruir el entramado ideológico que compartían tanto los misioneros como los intelectuales peruanos. Los misioneros no solamente compartieron el espacio de producción ideológica de la República Aristocrática, sino que fueron también productores (y reproductores) de ella.

Pero, regresando a Guha, podríamos tener alguna posibilidad de captar la voz del subalterno a partir de una lectura a contrapelo de las fuentes. Ello nos abre a la posibilidad de percibir las voces ocultas del indígena que es representado como "inculto" o "vicioso". Lo más probable es que los indígenas no conocían esas representaciones sobre ellos. Sin embargo, las sentían en su práctica interrelacional cotidiana con los productores de esos discursos. Tomando discrecionalmente la idea de mímesis de Homi Bhabha (2002), esas construcciones representacionales contribuyeron a que el indígena creara una identidad que retomaba esas representaciones, no porque configuraran su autocomprensión identitaria, sino porque era la manera con la que podrían mantener su capacidad de negociación con una elite que le temía por su "incuria". Además, los misioneros necesitaban repetir ese discurso, no solo porque buscaban que los indígenas asumieran sus propios estereotipos, sino porque ellos mismos estaban construyendo su propia autorrepresentación.

Cuando en la década de 1960 las iglesias protestantes, ya entonces con dirigencias nativas mestizas, empezaron su proceso de nacionalización, reutilizaron el discurso misionero para conseguir su autonomía y desplazar al misionero. Ya eran "civilizados" como el misionero. Progresivamente los misioneros dejaron el control de las iglesias protestantes, aunque dejaron su sello ideológico en la mente de la nueva elite evangélica nacional.

\section{Referencias Citadas}

Arroyo, C.

2005 Nuestros Años Diez. La Asociación Pro-Indígena, el Levantamiento de Rumi Maqui y el Incaísmo Modernista. Libros en Red, s.l.

Bastian, J. P.

1990 Protestantes, Liberales y Francmasones, Sociedades de Ideas y Modernidad en América Latina. Fondo de Cultura Económica, México D.F.

Bhabha, $\mathrm{H}$.

2002 El lugar de la cultura. Manantial. Buenos Aires.

Browning, W. J. Ritchie y K. Grubb

1930 The West Coast Republics in South America. Chile, Peru and Bolivia. World Dominion Press, Londres.

Bruno-Jofré, R.

1988 Methodist Education in Peru. Social Gospel, Politics, and American Ideological and Economic Penetration 1888-1930. Canadian Corporation for Studies in Religion, Waterloo.

Butler, $\mathrm{S}$

2008 Travel Narratives in Dialogue: Contesting Representations of Nineteenth-Century Peru. Peter Lang, Nueva York.

Encinas, J.A.

1915 "El valor del protestantismo en el Perú". El Mensajero, 3: 5-6.

Fairclough, N.

1992 Discourse and Social Change. Polity Press, Cambridge.
Fonseca, J.

2002 Misioneros y Civilizadores. Protestantismo y Modernización en el Perú (1915-1930). Fondo Editorial de la PUCP, Lima.

Fonseca, J.

2005 "Protestantismo, indigenismo y el mundo andino (1900-1930)". Más Allá de la Dominación y la Resistencia. Estudios de Historia Peruana, editado por P. Drinot y L. Garofalo, pp. 282-311. Instituto de Estudios Peruanos, Lima.

Gómez, L.

2009 Iluminados y Tránsfugas: Relatos de Viajeros y Ficciones Nacionales en Argentina, Paraguay y Perú. IberoamericanaVervuet, Madrid-Frankfurt.

Guha, R.

1999 "La prosa de la contrainsurgencia". Pasados Postcoloniales, editado por S. Dube. El Colegio de México, México D.F.

Guinness, G.

1909 Peru. Its Story, People and Religion. Morgan \& Scott, Londres.

Guinness, $\mathrm{H}$.

1906 The Children of the Sun. The Tragic Story of the Inca Indians of Peru. Regions Beyond Missionary Union, Londres.

Jarrett, J.

1908 Fifteen Years in Peru. Regions Beyond Missionary Union, Londres. 
Johnston, A.

2003 Missionary Writing and Empire, 1800-1860. Cambridge University Press, Cambridge.

Laing, $\mathrm{K}$.

2018 “Only Connect": Irish Women's Voices, Latin America $\&$ the Irish Women's Writing Network. Irish Migration Studies in Latin America, 9: 57-71.

Mansilla, M.A., W. Muñoz y C. Piñones

2016 "El postpentecostalismo. La concepción de los migrantes peruanos y bolivianos evangélicos (quechuas y aymaras) sobre el pentecostalismo chileno". Diálogo Andino, 51: 81-91.

Mariátegui, J.C.

1955 [1928]. Siete ensayos de interpretación de la realidad peruana. Universitaria, Santiago de Chile.

Maturana, F.

2016 "Representación indígena en el área centro-sur andina. El caso de los uru-chipaya". Diálogo Andino, 50: 59-73.

Maxwell, E.L.

1921 Up and Down the Andes on a Burro. Pacific Press, Mountain View.

Migliori, A.

2013 La Construcción del Paisaje de la Sierra del Perú en el siglo XIX (Perspectiva desde los viajeros). Tesis para optar el título de Licenciado en Historia, Pontificia Universidad Católica del Perú, Lima, Perú.

Míguez Bonino, J.

1995 Rostros del protestantismo latinoamericano. Nueva Creación, Buenos Aires.

Newell, W.H.

1904 For Christ and Cuzco. Londres.

Pagden, A.

1993 European Encounters with the New World: From Renaissance to Romanticism. Yale University Press, New Haven.

Piedra, A.

2005 Evangelización protestante en América Latina. CLAI, Quito.
Pratt, M. L.

2010 Ojos Imperiales. Literatura de Viajes y Transculturación. Fondo de Cultura Económica, México.

Rader, M.

1926 Evangelizing Beyond the High Sierras. Inca Land, 2: 20.

Ramirez, L. E.

2007 British Representations of Latin America. University Press of Florida Gainesville, FL.

Rodríguez, M.T.

2010 "Vida y milagros. Neopentecostalismo en comunidades nahuas". Diálogo Andino, 36: 51-60.

Said, E.

1990 Orientalismo. Libertarias. Madrid.

Seiguer, $\mathrm{P}$.

2019 "'Los caminos de Penzotti'. Las misiones protestantes en América del Sur y la construcción de la laicidad". Iberoamericana, 19: 157-179.

Smith, T.W.

1918 "Manifestaciones de incultura", El Cristiano, 80: 68-69.

Spivak, G.

1988 Can the Subaltern Speak? Marxism and the Interpretation of Culture, editado por C. Nelson y L. Grossberg, pp. 271313. University of Illinois Press, Urbana.

Stahl, F.

1920 In the Land of the Incas. Pacific Press, Mountain View.

Sugirtharajah, R.S.

2009 La Biblia y el Imperio. Exploraciones Poscoloniales. Akal, Madrid

Tuninetti, A. T.

2001 Nuevas tierras con viejos ojos: viajeros españoles y latinoamericanos en Sudamérica, siglos XVIII y XIX. El Corregidor, Buenos Aires.

Valcárcel, L.

1972 [1927]. Tempestad en los Andes. Universo, Lima.

Notas

1 Algunos estudios recientes de la construcción de representaciones en comunidades indígenas evangélicas son los de Rodríguez (2010) entre los nahuas en México y Mansilla et al. (2016) entre los migrantes peruanos y bolivianos (quechuas y aymaras) en Chile.

2 Paula Seiguer (2019) muestra cómo la prensa y la literatura protestante desarrollaron una narrativa respecto de la figura de Penzotti para construir un "personaje" dentro de una especie de hagiografía protestante.

3 Acerca de las relaciones entre capitalismo y metodismo en el Perú ver Bruno-Jofré (1988).

4 En la introducción de su libro, Geraldine Guinness (1909) explica que la decisión de publicarlo partió de su interés personal. No obstante, en el apéndice incluye una apelación a contribuir con la obra de la Regions Beyond Missionary Union (RBMU). Otros, como el de Browning et al. (1930), parecen más bien productos escritos institucionales. De Guinness ver Laing (2018: 59-60).

5 John Jarrett fue un misionero de nacionalidad inglesa de la RBMU, agencia misionera británica interdenominacional fundada en 1894. Jarrett, uno de sus primeros misioneros, llegó a Perú ese mismo año. Trabajó en Lima, Cusco y Arequipa. En 1911, la RBMU se fusionó con otra agencia misionera, la South American Evangelical Mission, para formar la EUSA.

6 Todos los libros a los que haré referencia fueron publicados en inglés. Para facilitar la comprensión del artículo, he traducido las citas procedentes de ellos. 